\title{
Finite Element Analysis of Hybrid Excitation Axial Flux Machine for Electric Cars
}

\author{
Pelizari, A. \\ ademir.pelizari@usp.br-University of Sao Paulo \\ Chabu, I.E. \\ ichabu@pea.usp.br - University of Sao Paulo
}

\begin{abstract}
FEM analysis of a hybrid excitation brushless axial flux machine (HEBAFM) for traction electric vehicle purposes in order to compare with the results from an analytical method used to determine the flux densities in each part of the machine. The magnetic quantities of the proposed topology were investigated in order to obtain a satisfactory level of flux densities avoiding a possible saturation of the material. Keeping the magnetic induction under the saturation point, it will be feasible to increase the speed beyond the rated speed. The results from using the analytical method as well as via FEM simulation analysis presented a good approximation and are shown at the end of this paper.
\end{abstract}

Index Terms - electric traction motor; electric vehicle application; hybrid excitation axial flux machine; simulation of electric motors.

\section{INTRODUCTION}

DC motors haves been used for almost two centuries. This is easily explained not only because it can operate at the flux weakening region but also for its excellent torque response. In order to solve the problem of the exhaustive electromechanical maintenance in this type of machine, during the 1960s, permanent magnet brushless dc machines were developed. The drawback of these machines is the difficulty in controlling the speed, especially when flux weakening region operation is required. Hence the main purpose of this paper is a comparative study of a Hybrid Excitation Brushless Axial Flux Machine [1] topology proposed in Figure 1, using the finite element analysis via 3D simulation software and the analytical method to make its operation at the constant power region possible keeping the flux density level in the critical parts of the machine under the saturation point.

\section{THE AXIAL FLUX MOTOR EQUATION TORQUE}

The first step during the development of the topology was to predict the developed torque upon its main dimensions and magnetic variables of the machine. The developed torque equation of the double side axial flux motor can be calculated as follows [2]:

$$
\mathrm{T}_{\mathrm{d}}=2 \cdot \pi \cdot \mathrm{B}_{1 \mathrm{AVG}} \cdot \mathrm{A} \cdot\left[\mathrm{K}_{\mathrm{d}}-\mathrm{K}_{\mathrm{d}}^{3}\right] \cdot\left(\mathrm{RouT}^{3}\right.
$$



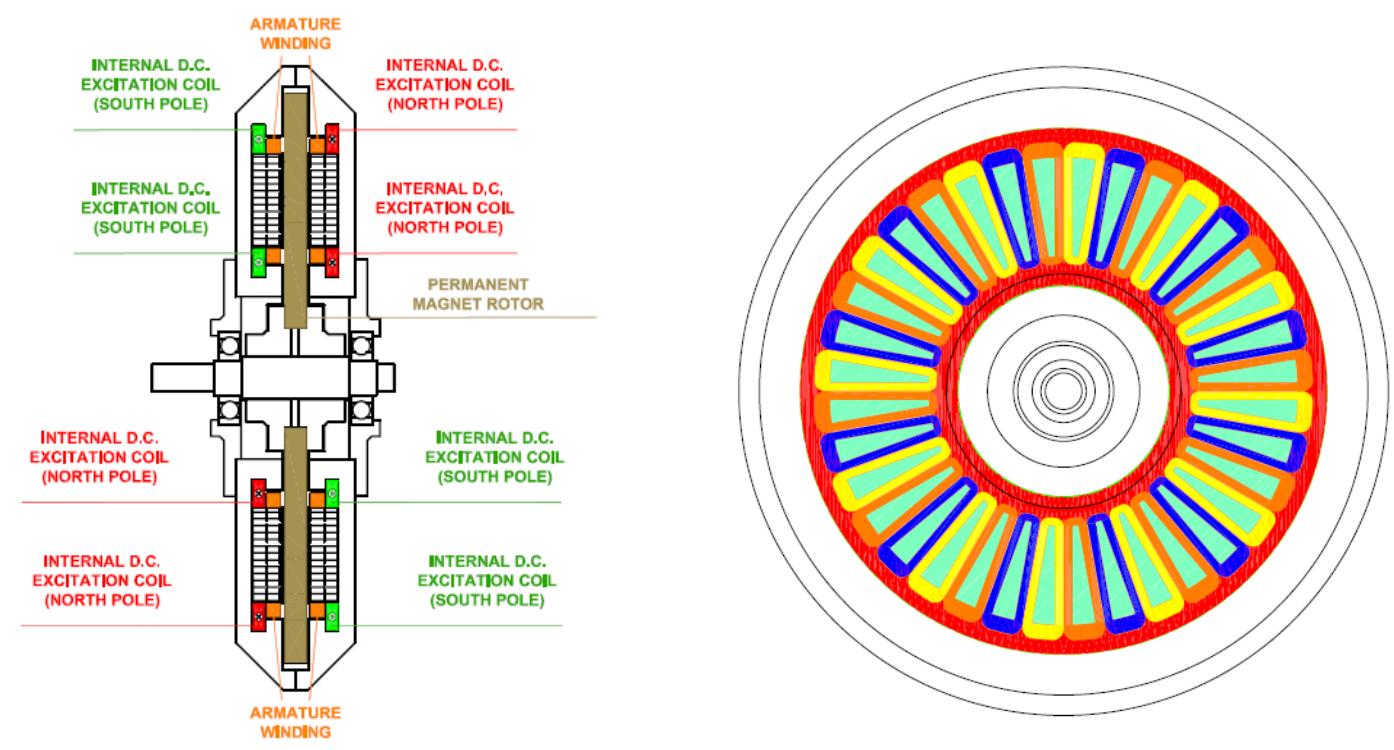

Fig.1. Side and frontal views of the axial flux topology proposed.

In (1), $\mathrm{R}_{\mathrm{OUT}}$ is the outer radius of the disc in meters, $\mathrm{A}$ is the rms linear current density, i.e., $\mathrm{Am} / 2^{-1 / 2}$ in Ampère.turns/meter, $\mathrm{B}_{1 \mathrm{AVG}}$ the fundamental air gap average flux density in Tesla, $\mathrm{K}_{\mathrm{d}}$ is the diameter factor of the disc. The constant Am is the peak of the linear current density and it can be calculated as:

$$
\mathrm{Am}=\mathrm{m}_{1} \cdot \sqrt{2} \cdot \mathrm{N}_{\mathrm{I}} \cdot \mathrm{I}_{\mathrm{A}} /\left(\pi \cdot\left(\mathrm{R}_{\mathbb{N}}+\left(\mathrm{R}_{\mathrm{out}}-\mathrm{R}_{\mathbb{N}} / 2\right)\right)\right.
$$

In (2), $\mathrm{m}_{1}$ represents the number of phases of the stator, $\mathrm{N}_{1}$ the number of turns of the armature winding and $\mathrm{I}_{\mathrm{A}}$ the phase current of the stator winding. The air gap average flux density in (1) can be obtained in terms of the air gap maximum flux density $\mathrm{B}_{\mathrm{g}}$, as in (3)

$$
\mathrm{B}_{1 \mathrm{AVG}}=(2 / \pi) \cdot \sqrt{2} \cdot \mathrm{Bg}_{\mathrm{g}} \cdot \sin (\alpha \cdot \pi / 2)
$$

The term $\alpha$ in (3) is the relationship between coil pitch and pole pitch. Therefore, once the average flux density has already been defined, the developed torque behavior can be viewed as in Figure 2 as a function of both linear current density and average flux density.

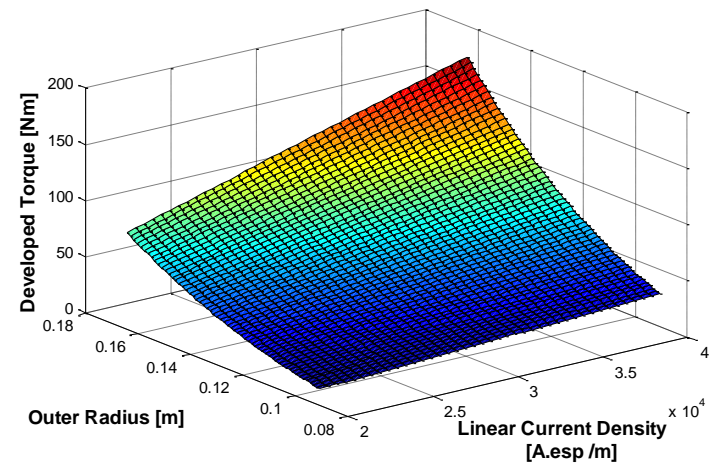

Fig.2. Developed Torque as Function of Linear Current Density and Air Gap Average Flux Density. 


\section{ARMATURE DESIGN}

In this step, the sizing of armature was based on its main dimensions obtained through the equations in section II as well as on its rated data. The general data and the rated characteristics of the hybrid excitation axial flux machine topology proposed are shown in Table I.

TABLE I - PROPOSED TOPOLOGY DATA.

\begin{tabular}{|l|l|c|}
\hline & \multicolumn{2}{|c|}{ General Data } \\
\hline 1 & Rated Power & $10 \mathrm{~kW}$ \\
\hline 2 & Three-Phase Supply Voltage & $440 \mathrm{~V}$ \\
\hline 2 & Synchronous Speed - $\left(\mathrm{N}_{\mathrm{S}}\right) \mathrm{e}\left(\mathrm{n}_{\mathrm{S}}\right)$ & $600 \mathrm{rpm}-10 \mathrm{rps}$ \\
\hline 3 & Maximum Linear Current Density $\left(\mathrm{A}_{\mathrm{M}}\right)$ & 38.000 \\
\hline 4 & Maximum Airgap Flux Density [9] & $0,65 \mathrm{~T}$ \\
\hline 5 & Max. Airgap Flux Weakening Density & $0,325 \mathrm{~T}$ \\
\hline 6 & Voltage Factor $(\in)$ & 0,9 \\
\hline 7 & Coil pitch / Pole pitch Ratio $\alpha$ & 0,637 \\
\hline
\end{tabular}

In this type of machine, due the greater disc diameter, the ratio of speed of the topology proposed was 600/1200 revolutions per second to avoid vibration of the machine, i.e., ratio of speed of 1:2 and therefore the air gap flux density ratio adopted was $2: 1$. Hence, the number of poles can be determined as:

$$
\mathrm{p}=(2 . \mathrm{f} .60) / \mathrm{N}_{\mathrm{s}}
$$

In (4), $\mathrm{f}$ is the rated frequency in $(\mathrm{Hz}), \mathrm{Ns}$ the synchronous speed in rpm. After calculating the number of poles, the next step was to obtain the average flux density $\mathrm{B}_{1 \mathrm{AVG}}$ as a function of peak air gap flux density calculation. Hence, the fundamental flux density per pole can be calculated as in (5):

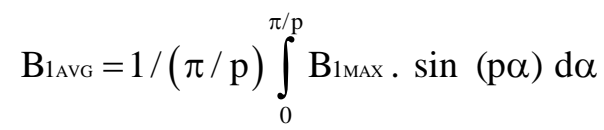

Based on average flux density per pole, the magnetic flux per pole is determined as

$$
\Phi_{\mathrm{POLE}}=\int_{\text {Rin }}^{\text {Rout }} \mathrm{B}_{1 \mathrm{AVG}} . \mathrm{dSp} \rightarrow \Phi_{\mathrm{POLE}}=\int_{\text {Rin }}^{\text {Rout }} \mathrm{B}_{\mathrm{AVG}} \cdot 2 \cdot \pi \cdot \mathrm{r} . \mathrm{dr} / \mathrm{p}
$$

Thus, replacing (6) in (5), results in

$$
\Phi_{\text {POLE }}=\alpha \cdot B_{1 \text { Max }} \cdot(\pi / 8 \cdot p p) \cdot\left[\left(\mathrm{D}_{\text {out }}\right)^{2}-\left(\mathrm{D}_{\mathrm{NN}}\right)^{2}\right]
$$

Since $\mathrm{K}_{\mathrm{d}}$ is a diameter factor it can be obtained as

$$
\mathrm{Kd}=\text { Dout } / \text { DiN }
$$

Substituting the $\mathrm{K}_{\mathrm{d}}$ factor in (8), after some mathematical treatment results 


$$
\Phi_{\text {POLE }}=\alpha \cdot B_{1 \text { Max }} \cdot(\pi / 8 \cdot \mathrm{pp}) \cdot \text { Dout }^{2}\left(1-\mathrm{Kd}^{2}\right)
$$

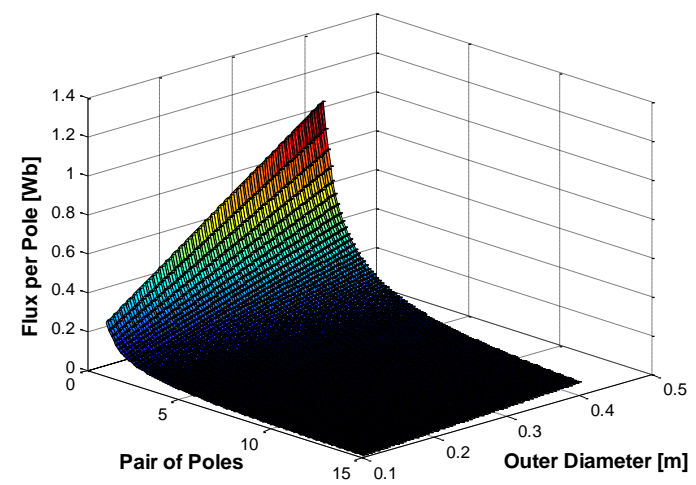

Fig.3. Relationship among $\Phi_{\text {POLE }}, D_{\text {OUT }}$ and pair of poles.

The Figure 3 illustrates the dependence of the flux per pole as a function of $\mathrm{D}_{\mathrm{OUT}}$ and pair of poles. $K_{D}$ is the dimension factor as a function of $K_{d}$, which can be calculated as

$$
\mathrm{K}_{\mathrm{D}}=0.125 \cdot\left(1+\mathrm{K}_{\mathrm{d}}\right) \cdot\left(1-\mathrm{K}_{\mathrm{d}}^{2}\right)
$$

Hence, the outer diameter of the axial flux motor disc can be determined as follows [4]

$$
\mathrm{D}_{\text {out }}=\left(\in . \mathrm{P}_{\mathrm{N}} /\left(\pi^{2} \cdot \mathrm{K}_{\mathrm{D}} \cdot \mathrm{K}_{\omega 1} \cdot \mathrm{n}_{\mathrm{s}} \cdot \mathrm{B}_{\mathrm{MAx}} \cdot \mathrm{Am}_{\mathrm{M}} \cdot \eta \cdot \cos \varphi\right)\right)^{1 / 3}
$$

Referring to (11) the outer diameter variation can be seen as in Figure 4 since the $K_{D}, K_{\omega 1}, n_{s}$ factors are constant.

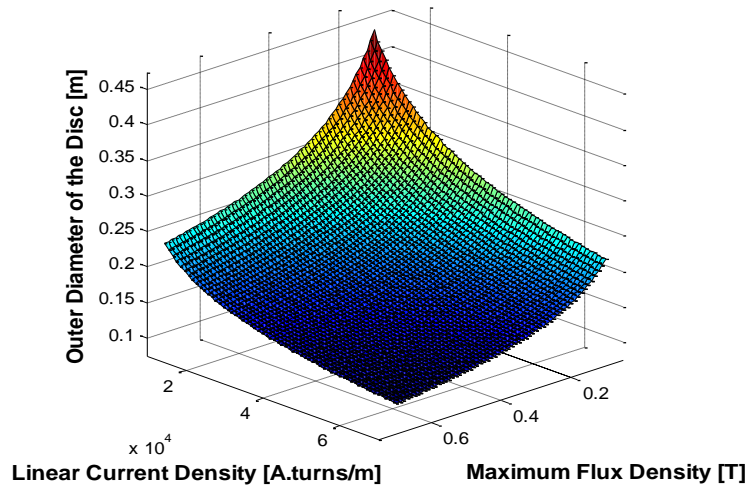

Fig.4. Behavior of Dout $=f\left(B_{1 M A X}(T), A_{M}(A . t / m)\right.$.

And the inner diameter is consequently

$$
\mathrm{D}_{\mathrm{IN}}=\mathrm{D}_{\text {out }} / \sqrt{3}
$$

The armature data and its main characteristics are presented in Table II. 
TABLE II - ARMATURe DATA.

\begin{tabular}{|l|l|c|}
\hline Item & Armature \\
\hline 1 & Armature Core & FeSi \\
\hline 2 & Isotropic Radial Orientation & NGOES E 230 \\
\hline 3 & Type & Core-Slot \\
\hline 4 & Outer Diameter $\left(\mathrm{D}_{\mathrm{OUT}}\right)$ & $0,313 \mathrm{~m}$ \\
\hline 5 & Inner Diameter $\left(\mathrm{D}_{\mathrm{IN}}\right)$ & $0,181 \mathrm{~m}$ \\
\hline 6 & Number of Slots & 36 \\
\hline 7 & Diameter Factor $\left(\mathrm{K}_{\mathrm{d}}\right)$ & 0,5773 \\
\hline 8 & Dimension Fator $\left(\mathrm{K}_{\mathrm{D}}\right)$ & 0,131 \\
\hline 9 & Stacking Factor $\left(\mathrm{K}_{\mathrm{STACK}}\right)$ & 0,9 \\
\hline 10 & Leakage Factor $\left(\mathrm{K}_{\mathrm{LEAK}}\right)$ & 0,1 \\
\hline
\end{tabular}

As the topology is a double side stator machine, the number of turns per phase per stator can be calculated as

$$
\mathrm{N}_{1}=\in \cdot \mathrm{V}_{1} /\left(\pi \cdot \sqrt{2} . \mathrm{f} . \mathrm{K}_{\omega 1} . \Phi_{\mathrm{POLE}}\right)
$$

Since both sides of the armature windings were in series wye connection (Y), the electric current of the armature can be determined by

$$
\mathrm{I}_{\mathrm{A}}=\mathrm{P}_{\mathrm{N}} /\left(\mathrm{m}_{1} \cdot 2 \cdot\left(\mathrm{V}_{\mathrm{L}} / \sqrt{3}\right) \cdot \cos \varphi \cdot \eta\right)
$$

Thus, Table III summarizes the main data of the armature winding.

TABLE III - ARMATURE Winding DATA.

\begin{tabular}{|l|l|c|}
\hline Item & Armature Winding Data \\
\hline 1 & Type of Winding & Concentrated \\
\hline 2 & Number of Layers & 1 \\
\hline 3 & Number of Phases $\left(\mathrm{m}_{1}\right)$ & 3 \\
\hline 4 & Number of Poles $(\mathrm{p})$ & 24 \\
\hline 5 & Number of Coils $\left(\mathrm{N}_{\mathrm{COILS}}\right)$ & 36 \\
\hline 6 & Number of Turns per Phase $\left(\mathrm{N}_{1}\right)$ & 243 \\
\hline 7 & Number of Turns / Coil & 20 \\
\hline 8 & Number of parallel paths $\left(\mathrm{a}_{\mathrm{W}}\right)$ & 4 \\
\hline 9 & Winding Factor $\left(\mathrm{K}_{\omega 1}\right)$ & 1 \\
\hline 10 & Rated Frequency $(\mathrm{f})$ & $120 \mathrm{~Hz}$ \\
\hline 11 & Rated Current $\left(\mathrm{I}_{\mathrm{A}}\right)$ & $15 \mathrm{~A}$ \\
\hline
\end{tabular}

Using (1), the three-phase calculated developed torque in both conditions can be viewed in Table IV. 
TABLE IV - ANALYTICAL TORQUE RESUlT.

\begin{tabular}{|l|l|c|}
\hline Item & Calculated Torque \\
\hline 1 & Three-Phase Developed Torque (Td)-Rated & $145,76 \mathrm{Nm}$ \\
\hline 2 & Three-Phase Developed Torque (Td)-Weake & $72,88 \mathrm{Nm}$ \\
\hline
\end{tabular}

\section{HYBRID EXCITATION DESIGN}

To avoid disc vibration, a ratio of speed of 600/1200 rpm was selected, thus, a maximum air gap flux density of $0.65 \mathrm{~T}$ produced by hybrid excitation for $600 \mathrm{rpm}$ was adopted herein. Consequently, at the flux weakening region, half the maximum air gap flux density, for a maximum speed of 1200 rpm, only PM excitation was considered. Basically, the hybrid excitation [5,6] proposed is composed of two systems as in Figures 5a and 5b: one system consists of 2 pairs of coils with 875 turns allocated at the outer and the inner part of the armature and fixed at the cover, which produces up to $0.325 \mathrm{~T}$ controlled by a d.c. source with maximum voltage of $100 \mathrm{~V}$. The latter is a permanent magnet system as in Figure $5 \mathrm{~b}$ composed of $24 \mathrm{NdFeB}-35$ permanent magnets fixed to the rotor which produces $0.325 \mathrm{~T}$. The main concern is to prevent saturation from occurring in the ferromagnetic cores, for instance, teeth, yokes or even in the cover, since that not only one, but two armature windings provide magnetic flux through the rotor.

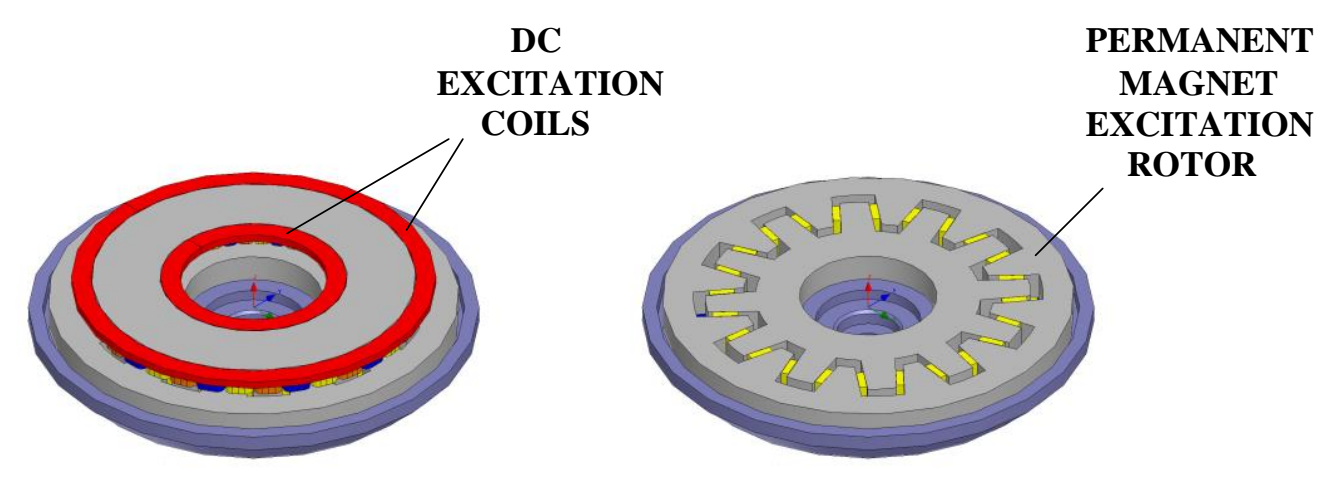

a)

b)

Fig.5. Excitation system.

a) Detail of the dc excitation coils. b) PM excitation.

A magnetic equivalent circuit was designed in order to calculate the flux densities in the most relevant parts of the topology. Figures 6 and 7 illustrate the pathway flux and Figures 8 and 9 the equivalent circuit with both excitation systems. 


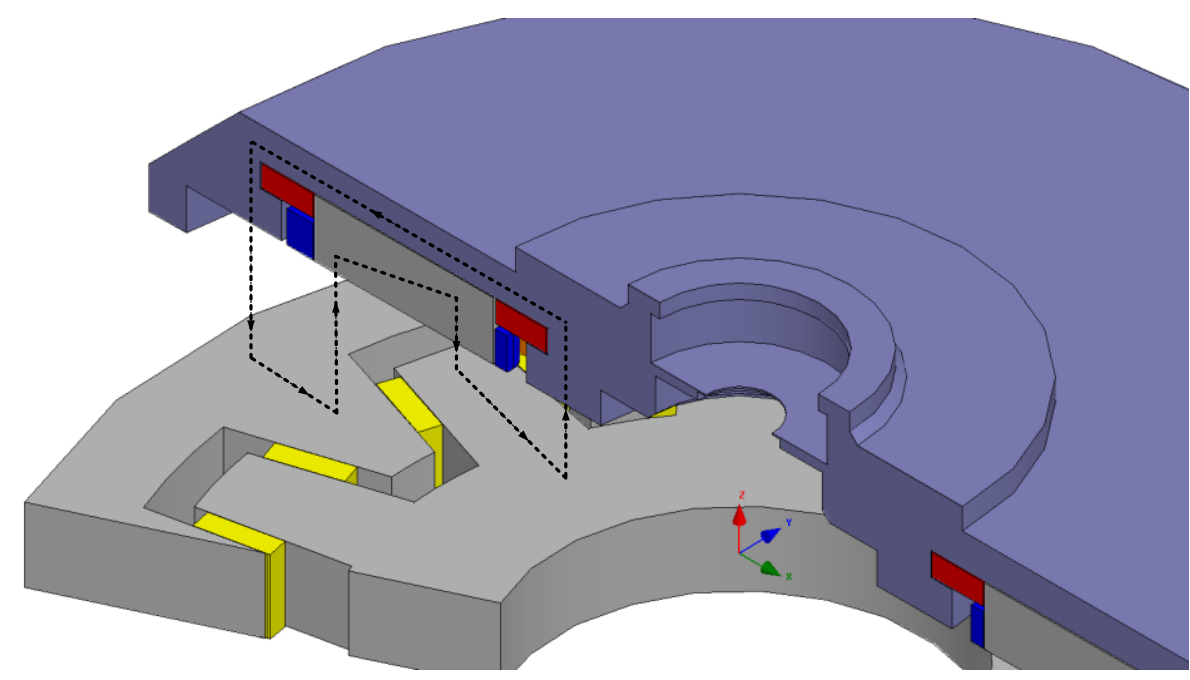

Fig. 6. Pathway of magnetic flux produced by the electric excitation.

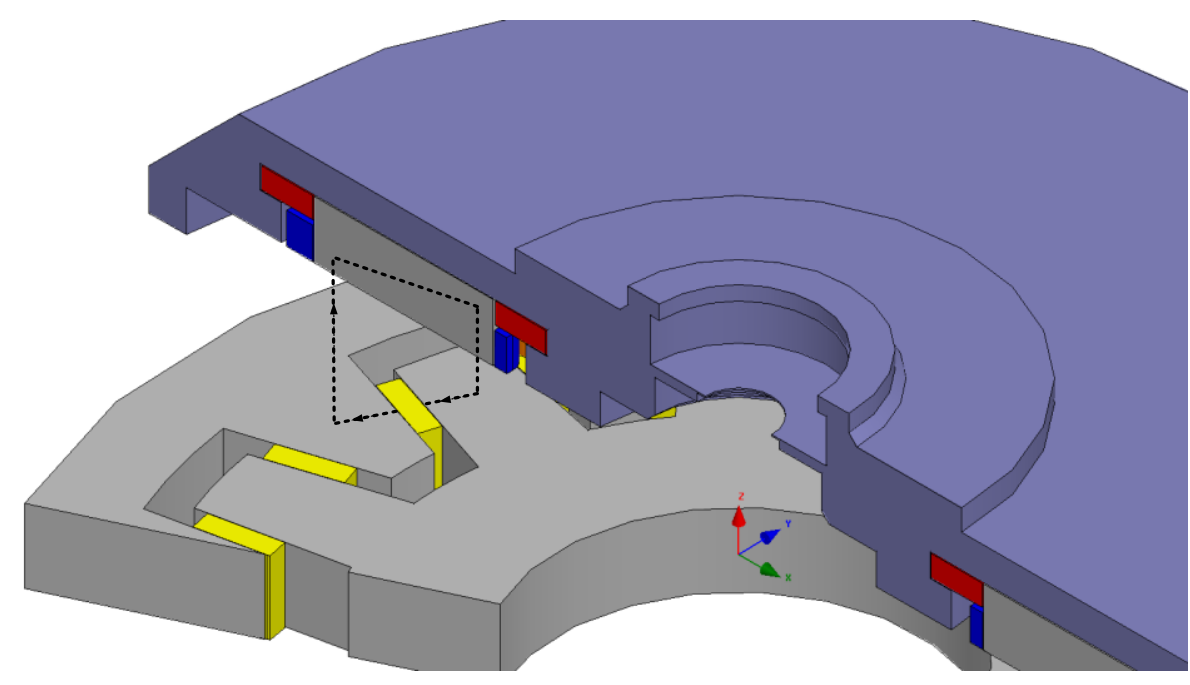

Fig. 7. Pathway of magnetic flux produced by PM excitation

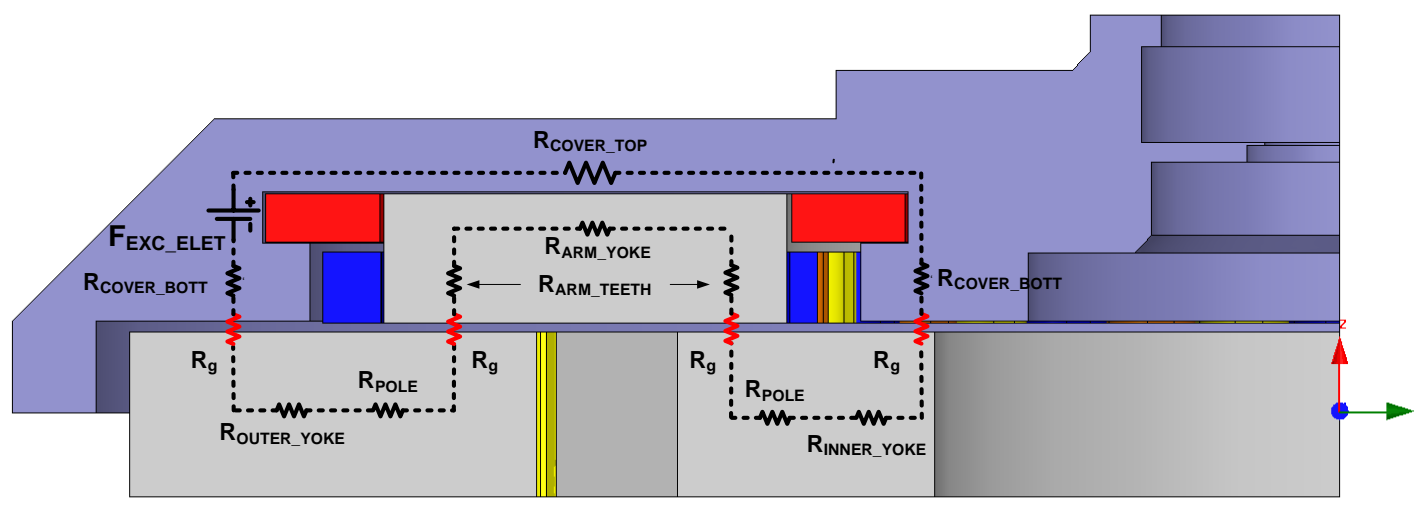

Fig. 8. Magnetic equivalent circuit due to the electric excitation. 


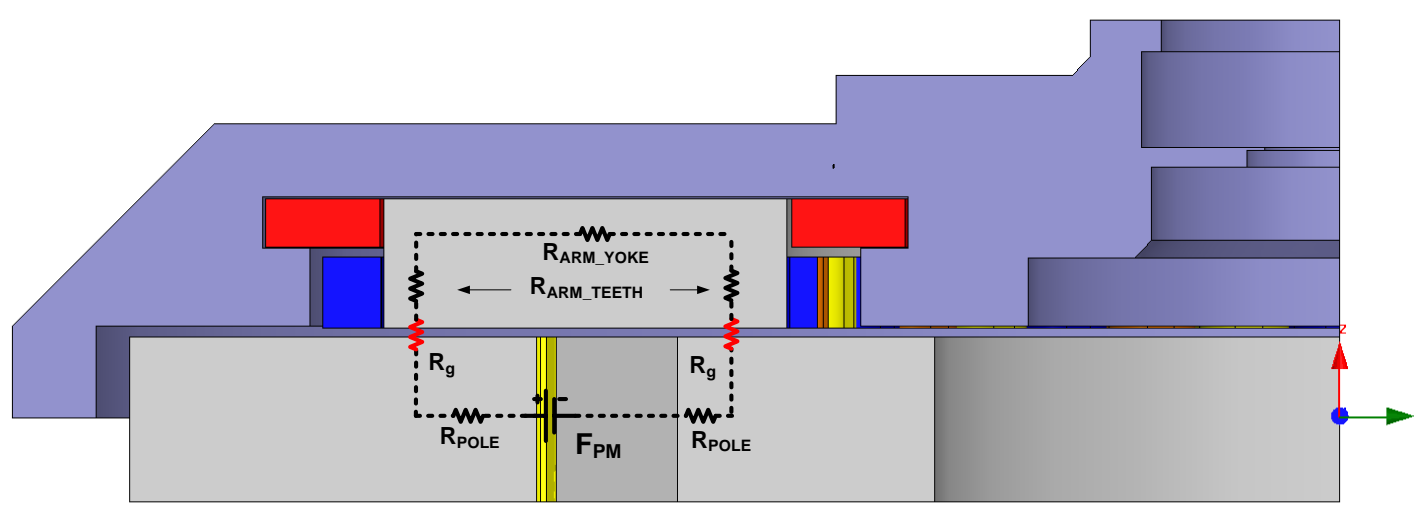

Fig.9. Magnetic equivalent circuit due to the PM excitation.

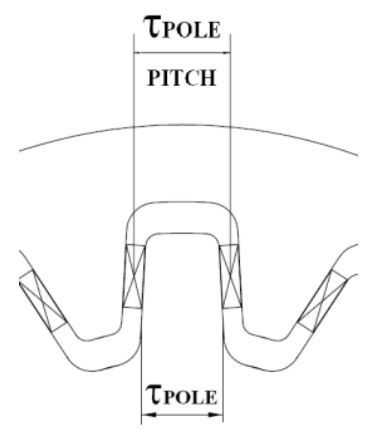

Fig.10. Detail of the rotor pole.

Referring to Figure 10, average flux density $\mathrm{B}_{1 \mathrm{AVG}}$ becomes:

$$
\mathrm{B}_{1 \mathrm{AVG}}=\left(\tau_{\mathrm{POLE}} / \tau_{\mathrm{POLE}_{-} \mathrm{PITCH}}\right) \cdot \mathrm{Bg}_{\mathrm{g}}
$$

From (15), the flux per pole can be determined since $S_{\mathrm{P}}$ is the area of the pole

$$
\Phi \text { POLE }=B_{1 A V G} \cdot S_{P}
$$

Since the flux per pole is produced by two stators, the flux density at the pole as a function of a minimum area as in Figure 11, becomes:

$$
\text { BMIN_AREA }=2 \cdot \text { ФPOLE } \cdot \mathrm{KLEAK}_{\mathrm{L}} / \mathrm{SP}_{-} \text {MIN }
$$




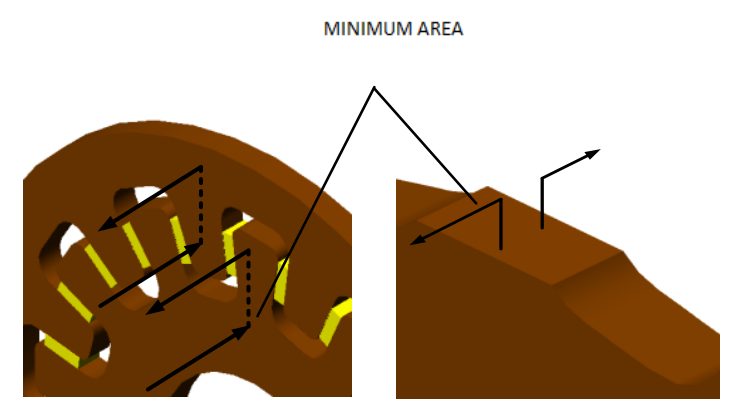

Fig.11. View of the magnetic flux pathway in the rotor and the minimum area of the pole.

The flux per pole at the inner yoke of the rotor can be determined by

$$
\Phi_{\text {INNER_YOKE }}=\Phi_{\text {POLE }} . K_{\text {LEAK }} .2 \mathrm{p} / 2
$$

Hence the flux density at the inner yoke of the rotor becomes

$$
\text { BINNER_YOKE }_{-}=\left(\Phi_{\text {INNER_YOKE }}\right) / \text { SINNER_YOKE }_{\text {INSTACK }}
$$

The flux density at the outer yoke of the rotor is

$$
\text { BOUTER_YOKE }=(\text { ФOUTER_YOKe }) / \text { SOUTER_YOKE } . \text { KSTACK }
$$

And the flux density at the teeth of the armature can be calculated as

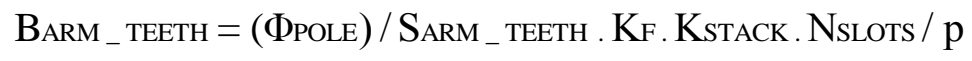

In (21), the term $\mathrm{S}_{\text {ARM_TEETH }}$ represents the area of the armature teeth, $\mathrm{K}_{\mathrm{STACK}}$ is the stacking factor. Lastly, the flux density at the yoke of the armature was calculated as in (22), i.e.

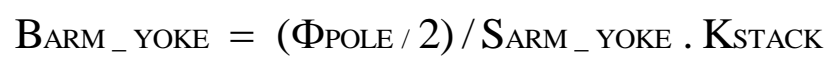

Using the magnetization curve given in figure 12 and the formulas from (15) up to (22), the flux density in each part of the machine can be calculated analytically. The calculated values are shown in Tables V, VI and VIII with double excitation, electric excitation and permanent magnet excitation only, respectively. 


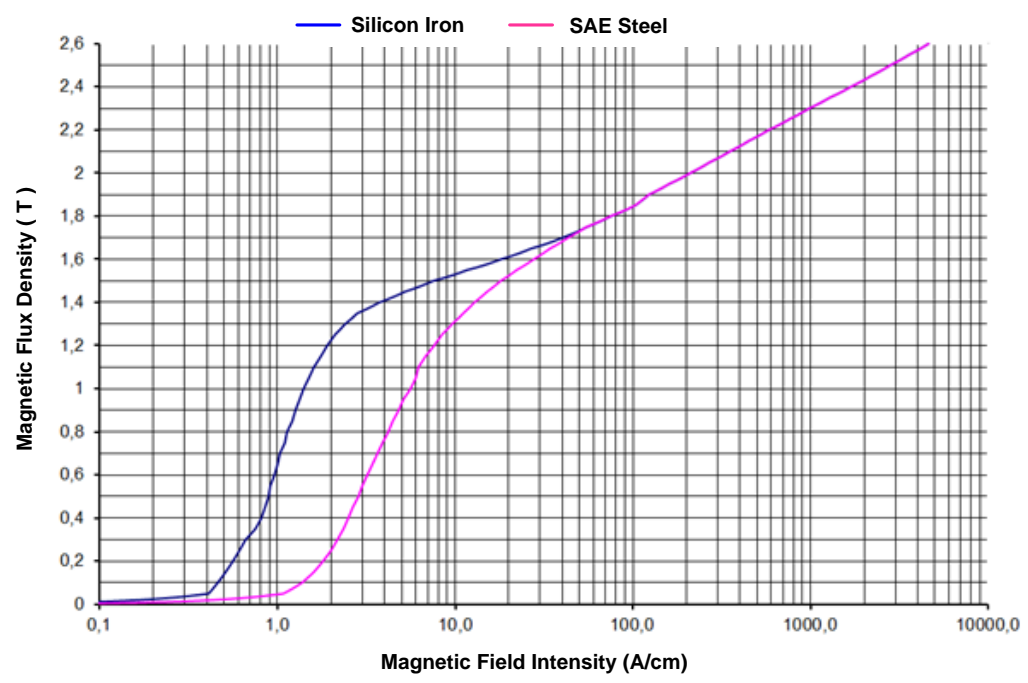

Fig.12._B-H Curve of silicon iron E230 and SAE 1020 steel.

Table V - Magnetic Circuit with Double Excitation.

\begin{tabular}{|c|c|c|c|}
\hline Part & \multicolumn{3}{|c|}{ Quantities } \\
\hline & B (T) & $\begin{array}{c}\text { Avg_length } \\
(\mathbf{m})\end{array}$ & MMF (A.t) \\
\hline Airgap & 0.65 & 0.0025 & 1034.51 \\
\hline Stator (NGOES E230) & & & 1.37 \\
\hline Arm_teeth & 0.98 & 0.01 & 1.01 \\
\hline Arm_yoke & 0.56 & 0.011 & \\
\hline Rotor (NGOES E230) & & & 0.22 \\
\hline Inner_yoke & 0.405 & 0.0027 & 0.17 \\
\hline Outer_yoke & 0.27 & 0.0027 & 41.2 \\
\hline Pole & 1.94 & 0.0027 & 268.6 \\
\hline Cover (SAE 1020 steel) & & & 586 \\
\hline Cover_bott & 1.68 & 0.068 & 1933.08 \\
\hline Cover_top & 1.76 & 0.1 & \\
\hline Total & & & \\
\hline
\end{tabular}

Table VI - Magnetic Circuit with Electric Excitation.

\begin{tabular}{|c|c|c|c|}
\hline Part & \multicolumn{3}{|c|}{ Quantities } \\
\hline & B (T) & Avg_length (m) & MMF (A.t) \\
\hline Airgap & 0.325 & 0.0025 & 517.25 \\
\hline Stator (NGOES E230) & & & 1.37 \\
\hline Arm_teeth & 0.49 & 0.01 & 1.01 \\
\hline Arm_yoke & 0.28 & 0.011 & \\
\hline Rotor (NGOES E230) & & & 0.22 \\
\hline Inner_yoke & 0.2 & 0.0027 & 0.17 \\
\hline Outer_yoke & 0.14 & 0.0027 & 41.2 \\
\hline Pole & 0.97 & 0.0027 & 268.6 \\
\hline Cover (SAE 1020 steel) & & & 586 \\
\hline Cover_bott & 0.84 & 0.068 & 1415.83 \\
\hline Cover_top & 0.88 & 0.1 & \\
\hline Total & & &
\end{tabular}


TABLE VII - Magnetic CirCuit with PM EXCITATION ONLy.

\begin{tabular}{|c|c|c|c|}
\hline Part & \multicolumn{3}{|c|}{ Quantities } \\
\hline & B (T) & $\begin{array}{c}\text { Avg_length } \\
\text { (m) }\end{array}$ & MMF (A.t) \\
\hline Airgap & 0.325 & 0.001 & 258.31 \\
\hline Stator (NGOES E230) & & & 0.880 \\
\hline Arm_teeth & 0.49 & 0.01 & 0.704 \\
\hline Arm_yoke & 0.28 & 0.011 & \\
\hline Rotor (NGOES E230) & & & 0.150 \\
\hline Inner_yoke & 0.202 & 0.0027 & 0.130 \\
\hline Outer_yoke & 0.135 & 0.0027 & 0.367 \\
\hline Pole & 0.97 & 0.0027 & 260 \\
\hline Total & & & \\
\hline
\end{tabular}

\section{FEM ANALYSIS}

This section presented the results of the finite element analysis in magnetostatic and transient analysis simulation via 3D software compare them with those of the analytical solution. The problem formulation in a magnetostatic study is

$$
-\frac{1}{\mu} \nabla^{2} \overrightarrow{\mathrm{A}}=\overrightarrow{\mathrm{J}}
$$

In (23), $\mathrm{J}$ is the current density, $\mathrm{A}$ is the magnetic vector potential and $\mu$ is the magnetic permeability of the medium. The current sources were imposed with their rated values which are $15 \mathrm{~A}$ in the armature winding and in electric excitation coils 1.6 A respectively according to the magnetomotive force calculated from Table VI. In this type of solution, the solver assumes that the electric current is uniformly distributed over the cross section of the coil and the direction of the current is determined by the arrows as in Figures 13a and 13b.

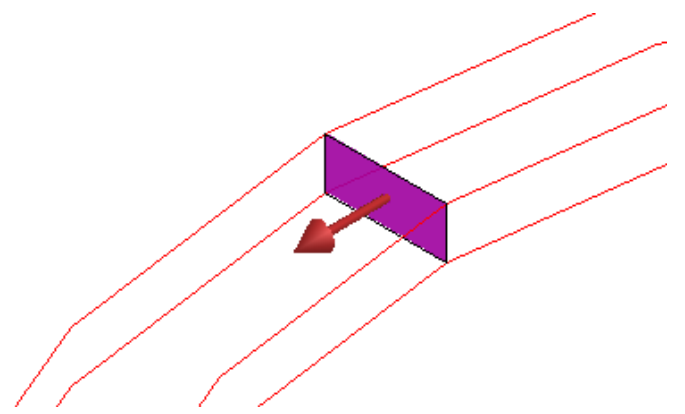

a)

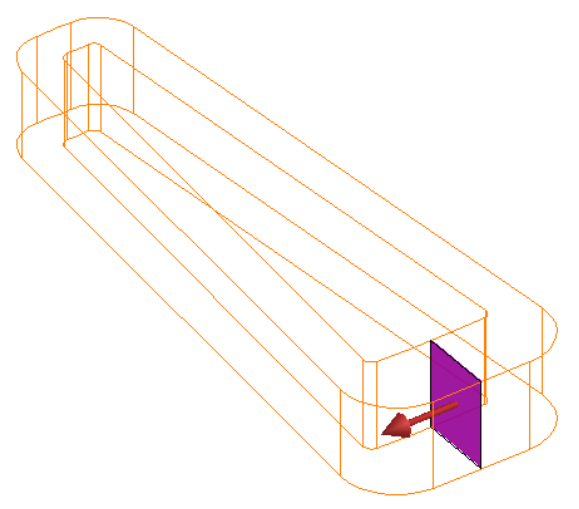

Fig.13. Paths of current.

a) Electric excitation b) Armature winding. 
Figures 14 and 15 illustrate the color map simulations of the topology in both conditions.
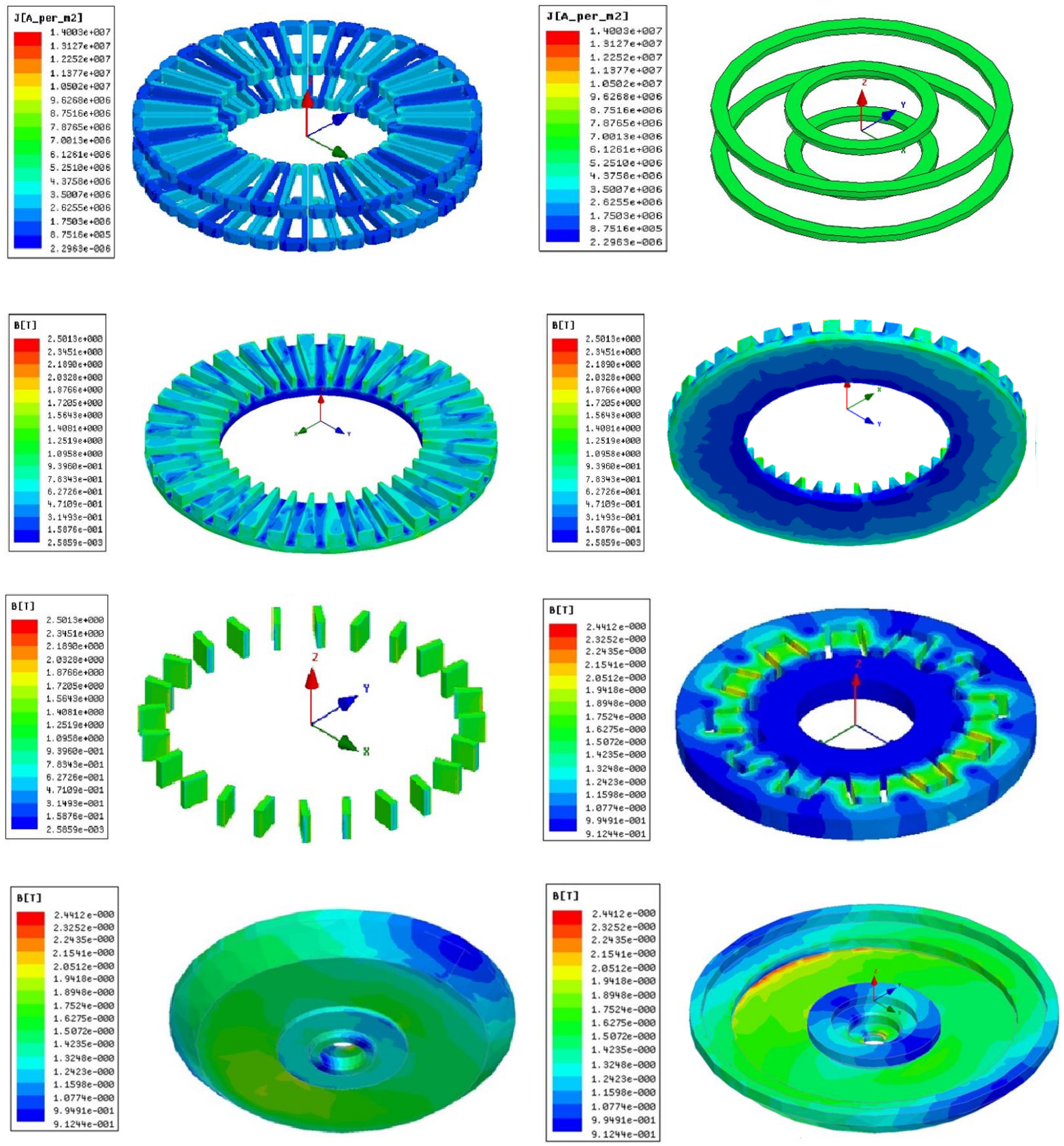

Fig.14. Color map results of the flux densities and current density under rated conditions. 

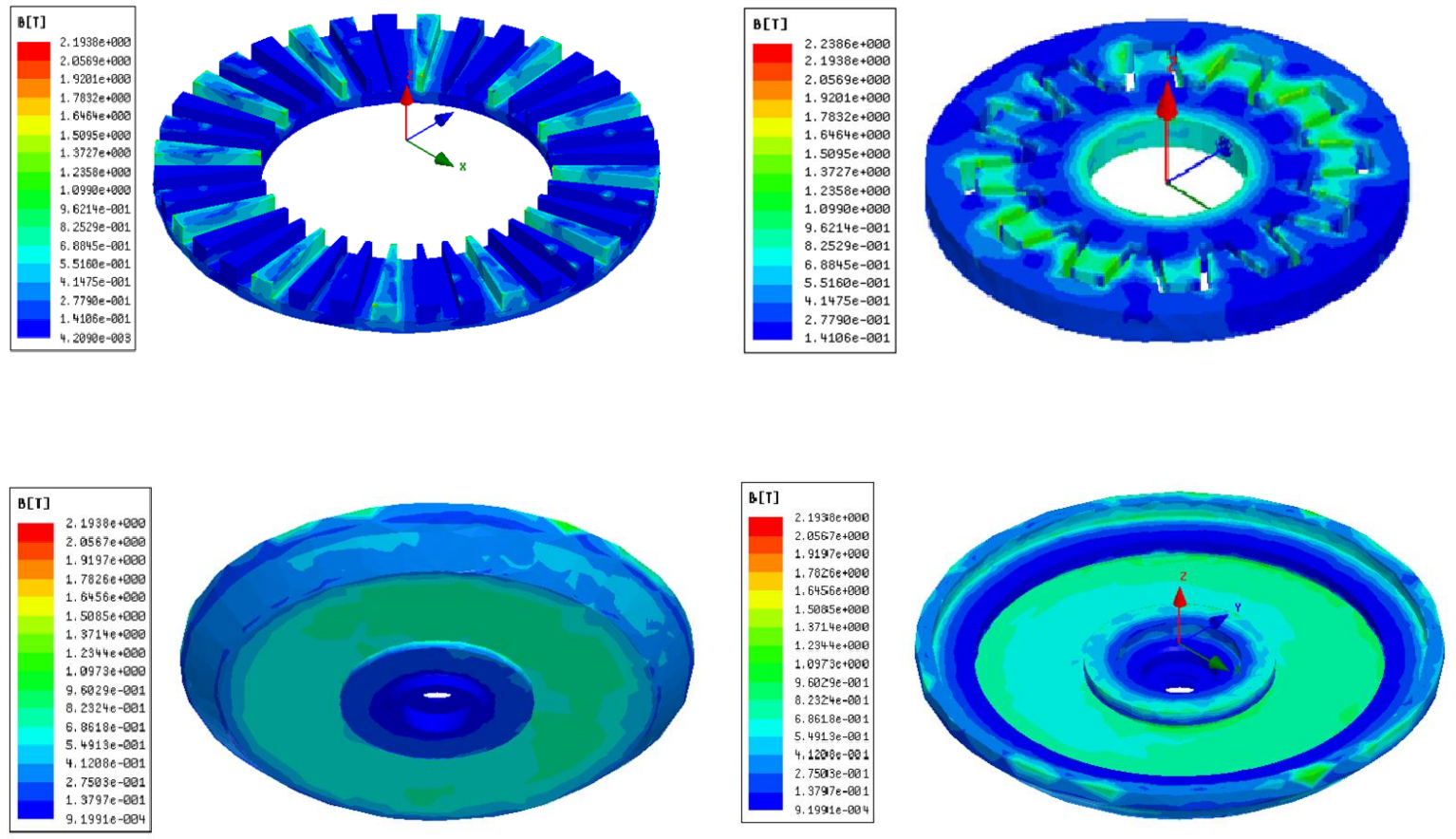

Fig.15. Color map of the flux densities density under flux weakening conditions.

In summary, the flux densities calculated in the motor as well as the FEM results are presented in Table VIII and Table IX, respectively

TABle VIII - FluX Density - Results - RATEd Condition.

\begin{tabular}{|l|c|c|c|}
\hline Item & Local & Analytical & FEM \\
\hline 1 & Arm_teeth & $0.98(\mathrm{~T})$ & $\begin{array}{c}+1.09(\mathrm{~T}) \\
-0.93(\mathrm{~T})\end{array}$ \\
\hline 2 & Arm_yoke & $0.56(\mathrm{~T})$ & $\begin{array}{c}+0.62(\mathrm{~T}) \\
-0.47(\mathrm{~T})\end{array}$ \\
\hline 3 & Inner_yoke & $0.405(\mathrm{~T})$ & $\begin{array}{c}+0.50(\mathrm{~T}) \\
-0.29(\mathrm{~T})\end{array}$ \\
\hline 4 & Outer_yoke & $0.27(\mathrm{~T})$ & $\begin{array}{c}+0.50(\mathrm{~T}) \\
-0.29(\mathrm{~T})\end{array}$ \\
\hline 5 & Pole & $1.94(\mathrm{~T})$ & $\begin{array}{c}+1.94(\mathrm{~T}) \\
-1.89(\mathrm{~T})\end{array}$ \\
\hline 6 & Cover_bott & $1.68(\mathrm{~T})$ & $\begin{array}{c}+1.75(\mathrm{~T}) \\
-1.62(\mathrm{~T})\end{array}$ \\
\hline 7 & Cover_top & $1.76(\mathrm{~T})$ & $\begin{array}{c}+1.75(\mathrm{~T}) \\
-1.62(\mathrm{~T})\end{array}$ \\
\hline
\end{tabular}

TABle IX - Flux Density - Results - Flux Weakening Condition.

\begin{tabular}{|l|c|c|c|}
\hline Item & Local & Analytical & FEM \\
\hline 1 & Arm_teeth & $0,49(\mathrm{~T})$ & $\begin{array}{c}+0.551(\mathrm{~T}) \\
-0.414(\mathrm{~T})\end{array}$ \\
\hline 2 & Arm_yoke & $0,28(\mathrm{~T})$ & $\begin{array}{c}+0.27(\mathrm{~T}) \\
-0.14(\mathrm{~T})\end{array}$ \\
\hline 3 & Pole & $0,97(\mathrm{~T})$ & $\begin{array}{c}+0.962(\mathrm{~T}) \\
-0.825(\mathrm{~T})\end{array}$ \\
\hline
\end{tabular}

A transient simulation analysis with constant speed imposed was carried out in both working 
conditions. The formulation of constant speed magnetic transient analysis is

$$
\nabla \times v \nabla \times \vec{A}=\vec{J}-\sigma \frac{\partial A}{\partial t}-\sigma \nabla V+\nabla \times H_{c}+\sigma v \times \nabla \times \vec{A}
$$

The constant $v, \sigma$ and $v$ are respectively the magnetic reluctivity, electric conductivity and constant speed in steady state regime. In the same equation, $\mathrm{V}$ is the scalar electric potential of the source, $\mathrm{Hc}$ is the coercive field intensity of the permanent magnets. Table IX presents the quantities used in the simulation

TABle X - Quantities of THE Simulation.

\begin{tabular}{|l|l|c|}
\hline & \multicolumn{2}{|c|}{ General Data } \\
\hline 1 & Scalar electric potential $(\mathrm{V})$ & $440 \mathrm{~V}$ \\
\hline 2 & Synchronous Speed - $(\mathrm{v})$ & $600 \mathrm{rpm}-1200 \mathrm{rpm}$ \\
\hline 3 & Coercive field intensity $(\mathrm{Hc})$ & $1006,513 \mathrm{k} \mathrm{A} / \mathrm{m}$ \\
\hline 4 & Frequency of the source & $120 \mathrm{~Hz}$ \\
\hline 5 & Synch armature winding inductance $\left(\mathrm{Ls}_{\mathrm{d}}\right)$ & $11,6 \mathrm{mH}$ \\
\hline 6 & Armature winding resistance $(\mathrm{R} 1)$ & $0,2240 \Omega$ \\
\hline 7 & Electric excitation resistance (Rexc_ext) & $24,33 \Omega$ \\
\hline 8 & Electric excitation resistance (Rexc_int) & $48,64 \Omega$ \\
\hline
\end{tabular}

For convenience, due the memory size of the computer, only $1 / 4$ of the geometry was simulated as in Figure 16.

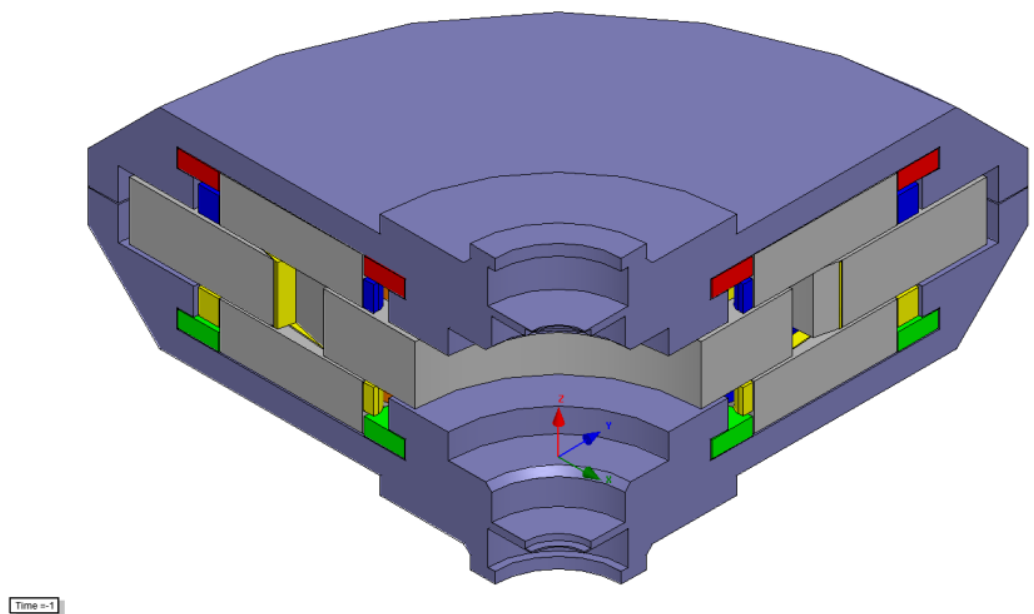

Fig.16. Detail of the simulated geometry.

The transient regime simulations with constant speed were carried out for two flux conditions, both of them an external electric circuit coupled. Figure 17a shows the electric circuit with a three-phase source connected to the armature winding and a dc rectifier converter feeding the electric excitation 
circuit. However, Figure $17 \mathrm{~b}$ presents only three-phase armature windings since there is no dc current at $1200 \mathrm{rpm}$.

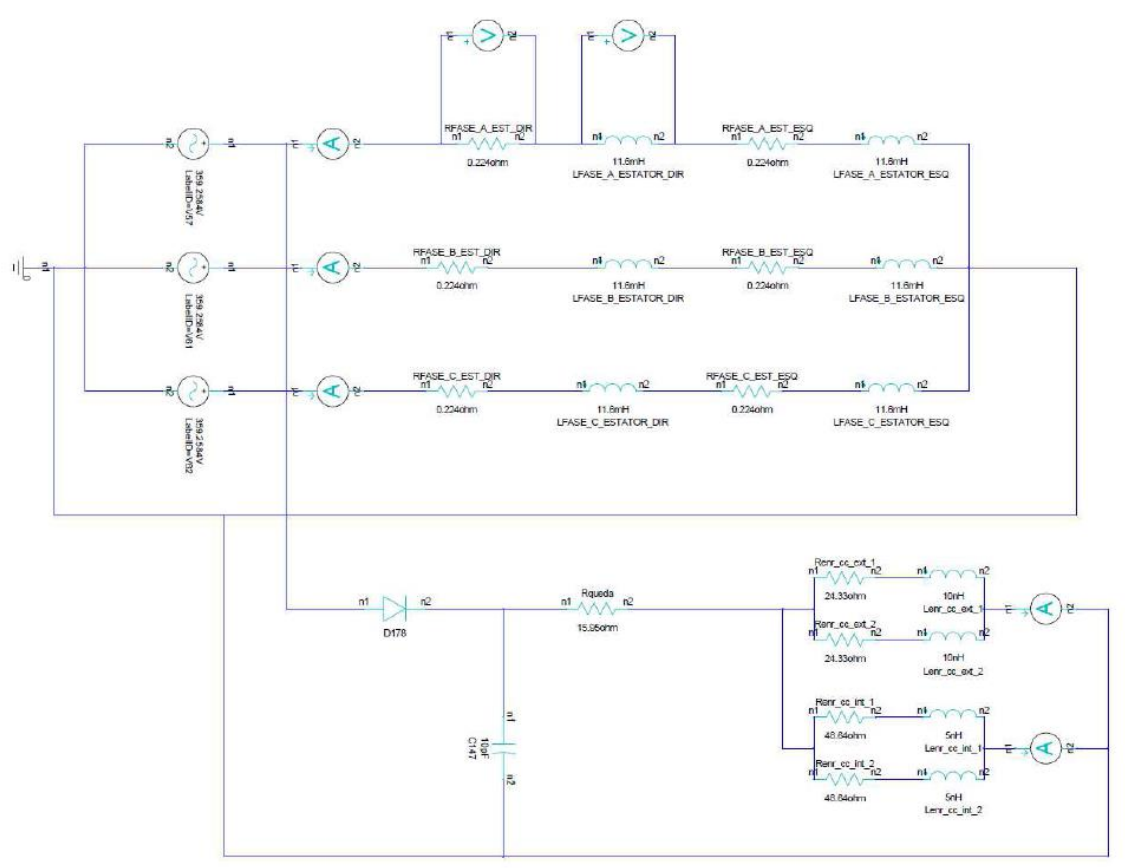

a)

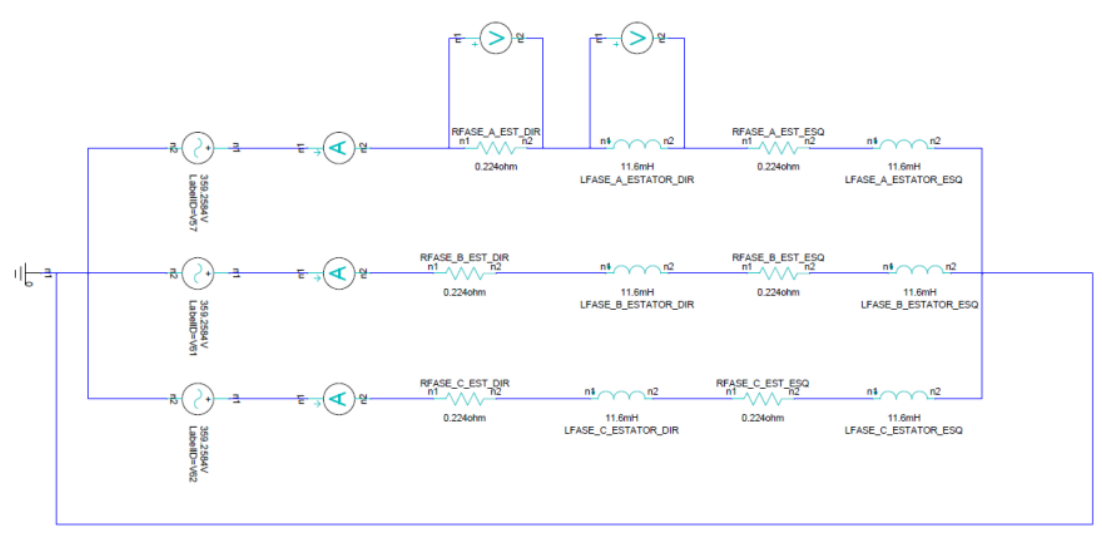

b)

Fig.17. External electric circuit coupled to the geometry simulated.

a) Rated conditions. b) Flux weakening conditions.

At the end of the simulation, the harmonics of field at steady state were extracted up to the $40^{\text {th }}$ harmonic, as illustrated in Figure 18 with double excitation at $600 \mathrm{rpm}$. 


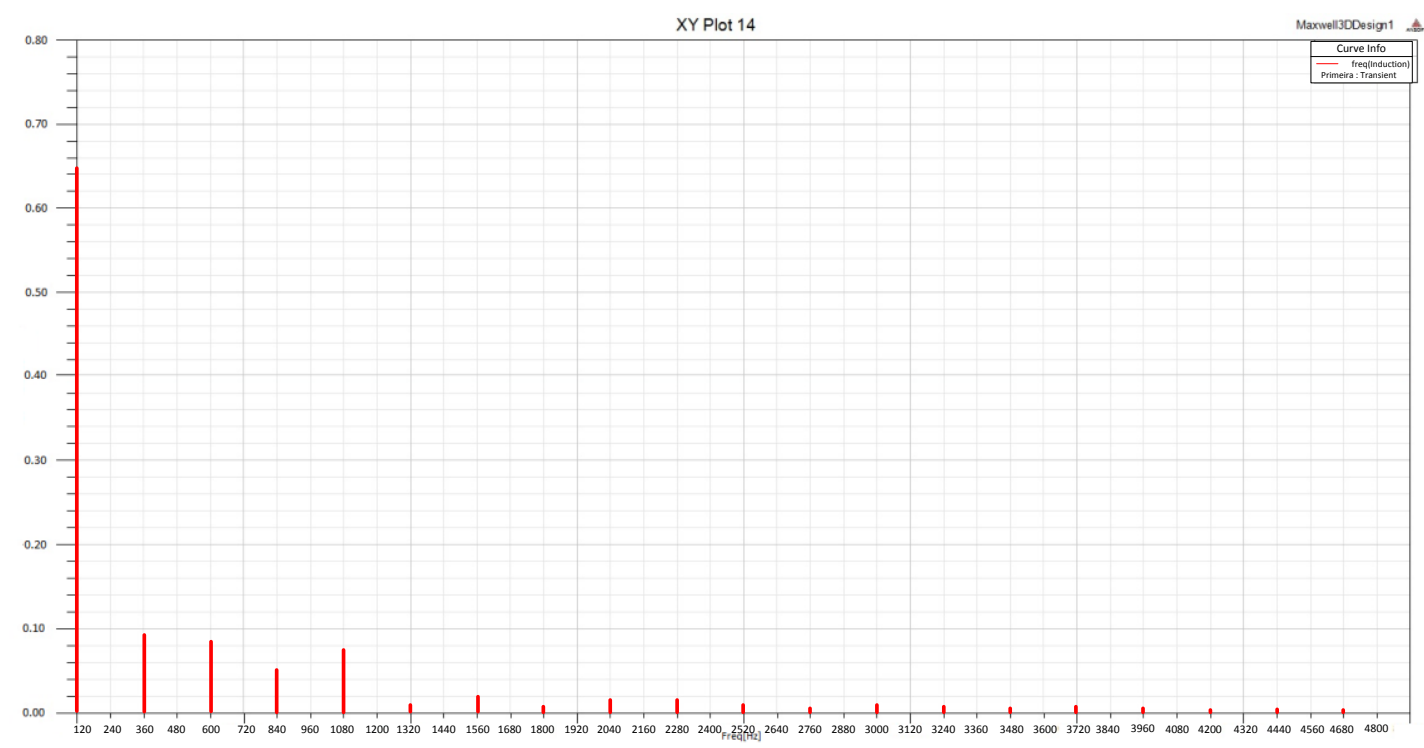

Fig.18. Flux density harmonics.

The developed torque calculated from the analytical method over the regions is presented in Figure 19 and the torque obtained through the simulation at rated speed and flux weakening region are presented in Figures 20a and 20b. Table XI summarizes the torque results obtained from the analytical method and simulation.

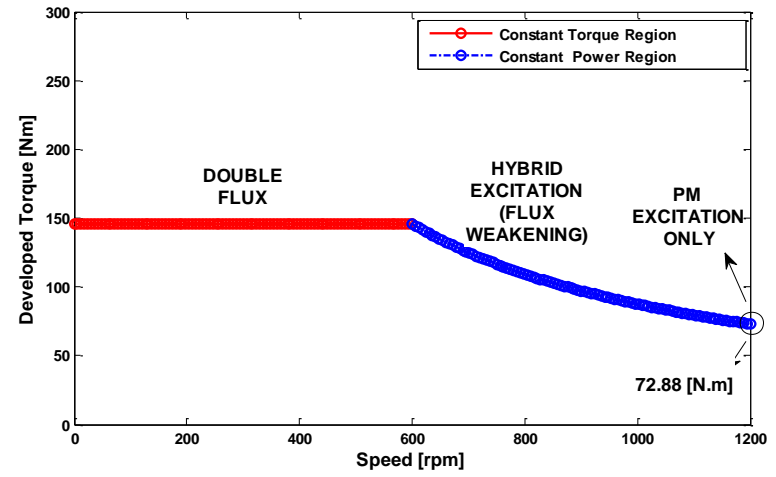

Fig. 19 - Analytical torque behavior.

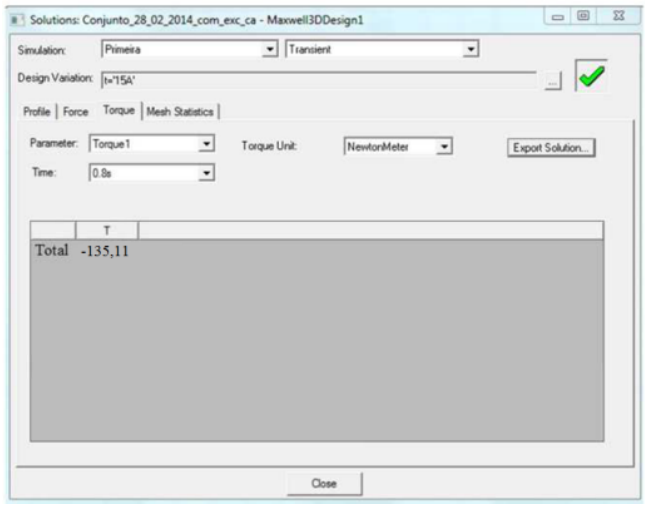

a)

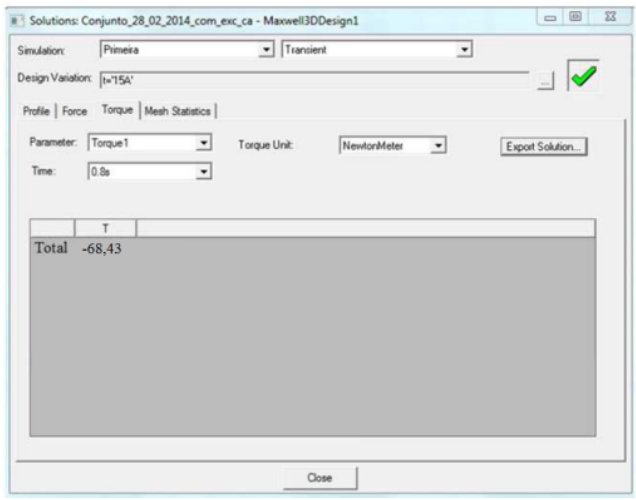

b)

Fig. 20 - Simulated torque. a) Rated conditions. b) Flux weakening region. 
TABle XI - DeVeloPed ToRQue - Results.

\begin{tabular}{|c|c|c|}
\hline \multicolumn{3}{|c|}{ Developed Torque } \\
\hline \multicolumn{3}{|c|}{ Rated Condition } \\
\hline Analytical & FEM & $\mathbf{\Delta \%}$ \\
\hline 145.76 & 135.11 & 7.3 \\
\hline \multicolumn{3}{|c|}{ Flux Weakening Condition } \\
\hline Analytical & FEM & $\mathbf{\Delta \%}$ \\
\hline 72.88 & 68.43 & 6.1 \\
\hline
\end{tabular}

\section{CONCLUSION}

The armature core and the rotor disc were designed based on the analytical method varying the dimensions such as area of the pole, area of the yokes and area of the teeth, thus preventing a critical situation which is magnetic saturation, since the saturation point of the ferromagnetic core used in this project was 2,1 Tesla. Through the analytical method and FEM simulations, the results from Table VII and Table VIII show that there was no saturation in any part of the machine, despite the high level of flux density at the minimum area of the pole. In spite of the greater losses at $120 \mathrm{~Hz}$, the efficiency achieved is satisfactory making the topology proposed possible. The torque results obtained analytically and simulated presented good approximation.

\section{REFERENCES}

[1] Caricchi, F.; Crescimbini, F., “Axial-flux permanent-magnet machine with water-cooled ironless stator", proc. IEEE Power Tech Conf., pp. 98-103, 1995.

[2] Gieras, J.F., R. Wang, and M. J. Kamper, “Axial flux permanent magnet brushless machines”, 2004.

[3] Wang, S.; Xia, Y.; Wang, X., "State of the art of hybrid excitation permanent magnet synchronous machines", Electrical Machines and Systems (ICEMS), International Conference on, pp.1004 - 1009, 2010.

[4] Xia, Y. ; Wang, S. ; Ma, M. ; Hao L.; Qiu A. ; Huang, S.; "Basic principles of hybrid excitation PM synchronous generator utilizing harmonic for excitation Electrical Machines and Systems (ICEMS), International Conference on, pp. $1010-1013,2010$

[5] Kefsi, L.; Touzani, Y.; Gabsi, M., "Hybrid Excitation Synchronous Motor control with a new flux weakening strategy", VPPC, IEEE, p.p. $1-5,2010$.

[6] Kamper, M.; Wang, R., "Analysis and performance evaluation of axial flux air-cored stator permanent magnet machine with concentrated coils", IEEE electric machines \& drives conference, 2007. 